\title{
BOOSTER MAIN MAGNET CYCLE MODELING AND \\ REPEATABILITY SIMULATION
}

\section{AD \\ BOOSTER TECHNICAL NOTE \\ NO. 151}

S. Y. ZHANG

OCTOBER 26, 1989

\section{ACCELERATOR DEVELOPMENT DEPARTMENT BROOKHAVEN NATIONAL LABORATORY UPTON, NEW YORK 11973}




\section{Introduction}

This note contains three aspects, i.e., 1) a modeling of Booster main magnet cycle, 2) a simulation of the cycle based on a thyristor simulation, and 3) a main magnet cycle repeatability study.

It is proposed that the Booster main magnet shall be controlled directly by a magnet current reference. Because of lack of an effective current servo the main magnet will be controlled in practice by a magnet voltage rather than a magnet current reference. The conversion of the magnet current reference to the associated magnet voltage reference shall be accomplished by a computer software. Therefore a good model for the main ring is needed. Such a model will be discussed and several important variables in the model will be indicated. Among many others, we formulate a Booster main magnet cycle by using such a model. The cycle includes the total magnet voltage, each station voltage, and the resulting magnet current. This work is performed in a scheme of a continuous system simulation.

By using thyristor converter simulation we then present a main magnet cycle simulation. This work is performed in a regime close to the real. This provides an opportunity to have a close look at some interesting issues such as the transient response, the ripple, the missing firing effect, and the power line disturbance effect.

Finally we present a main cycle repeatability simulation for the power line disturbances. The effects of tap changes of 1 percent in the $13.8 K \mathrm{~V}$ substation happened at $8 \mathrm{~ms}$ and $38 \mathrm{~ms}$ from the $t_{0}$ of the cycle are studied. With barely voltage regulation such disturbances result in magnet current errors close to 0.1 percent. Therefore other means of corrections is necessary in order to improve the main cycle repeatability.

We consider in this note only the Proton cycle. The Heavy Ion cycle can be studied in a similar way, the repeatability problem is less critical there. 


\section{Main Magnet Model and Main Cycle}

The models of the main magnet and the main power supply filter can be easily attained if several parameters are exactly known. In the following, we discuss the models in transfer function forms. The operator $s$ denotes in the time domain an operator of differentiation. For the main magnet, if the total inductance $L_{m}$ and total resistance $R_{m}$ are known then we have

$$
T_{m}=\frac{L_{m}^{-1}}{s+R_{m}} L_{m}^{-1}
$$

It is estimated that the total magnet inductance is about $138 \mathrm{mH}$ and the total resistance is about $115 m \Omega$, therefore

$$
T_{m}=\frac{7.246}{s+0.833}
$$

For the filter, the parameters are the choke inductance $L_{f}$, the filter main capacitance $C_{f 1}$, the damping capacitance $C_{f 2}$, and the damping resistance $R_{f}$. The transfer function of the filter can be written as

$$
T_{f}=\frac{\left(L_{f} C_{f 1}\right)^{-1} s+\left(L_{f} R_{f} C_{f 1} C_{f 2}\right)^{-1}}{s^{3}+\left(C_{f 1}+C_{f 2}\right)\left(R_{f} C_{f 1} C_{f 2}\right)^{-1} s^{2}+\left(L_{f} C_{f 1}\right)^{-1} s+\left(L_{f} R_{f} C_{f 1} C_{f 2}\right)^{-1}}
$$

The data available now are $L_{f}=1 \mathrm{mH}, C_{f 1}=122 \mu \mathrm{F}, C_{f 2}=609 \mu \mathrm{F}$ and $R_{f}=1.43 \Omega$, therefore, we have

$$
T_{f}=\frac{8.2 e 6 s+9.41 e 9}{s^{3}+6880 s^{2}+8.2 e 6 s+9.41 e 9}
$$

The data of the main magnet are the estimated and therefore when the installation is finished, the data shall be verified by a mcasurement. The data of the filter subject to the same and, in addition, a possible adjustment.

The model of the power supply station is more complicated, thus, is must be simplified. The model of the thy istor converter used now is a third order delay, i.e.,

$$
T_{t}=\frac{2.7 e 11}{s^{3}+22500 s^{2}+1.4 e 8 s+2.7 e 11}
$$


The DC gain of the thyristor converter is taken as a constant. The DC voltage output of each substation can reach $\pm 1100 \mathrm{~V}$, while the firing circuits receive 0 to $5 \mathrm{~V}$ as the reference range with $2.5 \mathrm{~V}$ as the zero reference, thus the gain for the thyristor converter is $G_{t}=440$. The regulator is a first order delay at a corner frequency $6.4 \mathrm{~Hz}$, and a DC gain $G_{r}=9$, therefore we have

$$
T_{r}=\frac{360}{s+40}
$$

The feedback coefficient is chosen as $F=0.004$. Thus, the transfer function of a substation is

$$
T_{s}=\frac{T_{t} G_{t} T_{r}}{1+T_{t} G_{t} T_{r} F}=\frac{4.28 e 16}{s^{4}+22540 s^{3}+1.41 e 8 s^{2}+2.76 e 11 s+1.82 e 14}
$$

All six substations are independent with each other, if the total reference is taken as the superposition of all substation references then the total power supply transfer function can be viewed as the same as $T_{\varepsilon}$. This model can be further simplified provided that the resulting errors can be tolerated. Some parameters such as those in the regulator is likely to be adjusted in the operation and this results in considerable variations on the transfer function.

By using the models we show a main magnet cycle plotted in Fig.1.1 that has a few milliseconds flatop at a level of about 2,365A. To achieve this we need a total voltage reference shown in Fig.1.2. The resulting voltage waveforms are shown in Fig.1.3. The solid line is the voltage after the filter, while the dotted line is the voltage before the filter. The reference waveform is also shown by the slashed line. Due to the limited gain and bandwidth the power supply output voltage cannot track the reference very closely. This is why the dynamic response of the power supply to the reference must be taken into account and the model $T_{s}$ cannot be replaced with a constant. A possible improvement of the tracking is discussed in [1]. If a gain of 0.5 in the scheme in [1] is applied for the feedforward correction, the tracking error can be reduced, and therefore the model $T_{s}$ 
may be simplified as a constant, see Fig.1.4, where the solid line is the improved power supply response to the reference.

The voltage references for all six substations are shown in Fig.1.5. In order to not lose control at the crucial peak current portion of the cycle, the falling time from full rectify to zero level for each station voltage reference is chosen to be longer than $10 \mathrm{~ms}$. The thyristor converter sampling period is enlarged during the falling as shown in Fig.1.6, where the total falling time is at $10 \mathrm{~ms}$ but the sampling period has already extended from the normal $0.69 \mathrm{~ms}$ to $1.14 \mathrm{~ms}$. It is obvious that a longer sampling period implies a certain loss of regulation.

\section{Main Magnet Cycle Modeling}

By using the thyristor converter simulation that includes the effect of the voltage regulation and commutation, etc. the voltage waveform of station 1 is shown in Fig.2.1, the detailed looks from 0 to $20 \mathrm{~ms}$ and from 30 to $50 \mathrm{~ms}$ are shown in Figs.2.2 and 2.3. In Fig.2.4 we show all the six substation waveforms. The resulting total voltage is shown in Fig.2.5. The voltage waveform after the filter is shown in Fig.2.6. Notice that the less important portion of the energy inversion is not included in the plots. The simulated magnet current is then shown in Fig.2.7. In Fig.2.8 we show the starting rising portion and in Fig.2.9 we show the flatop portion. The flatop portion shows a little overshoot and a certain extenl of the $1440 \mathrm{~Hz}$ ripple. The flatness can be easily adjusted in the operation provided a good repeatability is guaranteed. The $1,440 H z$ ripple is less than $0.1 A$ and therefore can be neglected. On the other liand, the subharmonic ripples may appear to be a problem. Thus, the substations are considered to be shut down at the flatop except one that keeps the magnct current flow. 


\section{Repeatability}

We assume that at $8 \mathrm{~ms}$ there is a $1 \%$ power line step disturbance. The voltage regulation loop then responds to correct the disturbance. The simulation is performed for all six substations by augmenting the amplitude of converter bridge waveform to 1.01 . Due to the voltage regulation, the converter firing varies to accommodate the power line amplitude variation. The resulting total voltage difference is shown in Fig.3.1. The power line amplitude variations reached to the bridges is increased from about $10 \mathrm{~V}$ to the largest $60 \mathrm{~V}$, the thyristor converter output responds as a step response, then a slop response. The magnet current error is shown in Fig.3.2 that indicates the peak current error can reach 2.25A. This therefore is not a negligible effect. The ratio of the current error and the magnet current is shown in Fig.3.3, where the peak is at $0.13 \%$, while at the flatop, $0.07 \%$

A same power line disturbance happened at about $38 \mathrm{~ms}$ gives rise of results that are shown in Figs.3.4 to 3.6 for the voltage difference, the error current and error ratio, respectively. The peak current error ratio is at $0.075 \%$, while at the flatop, $0.04 \%$. 


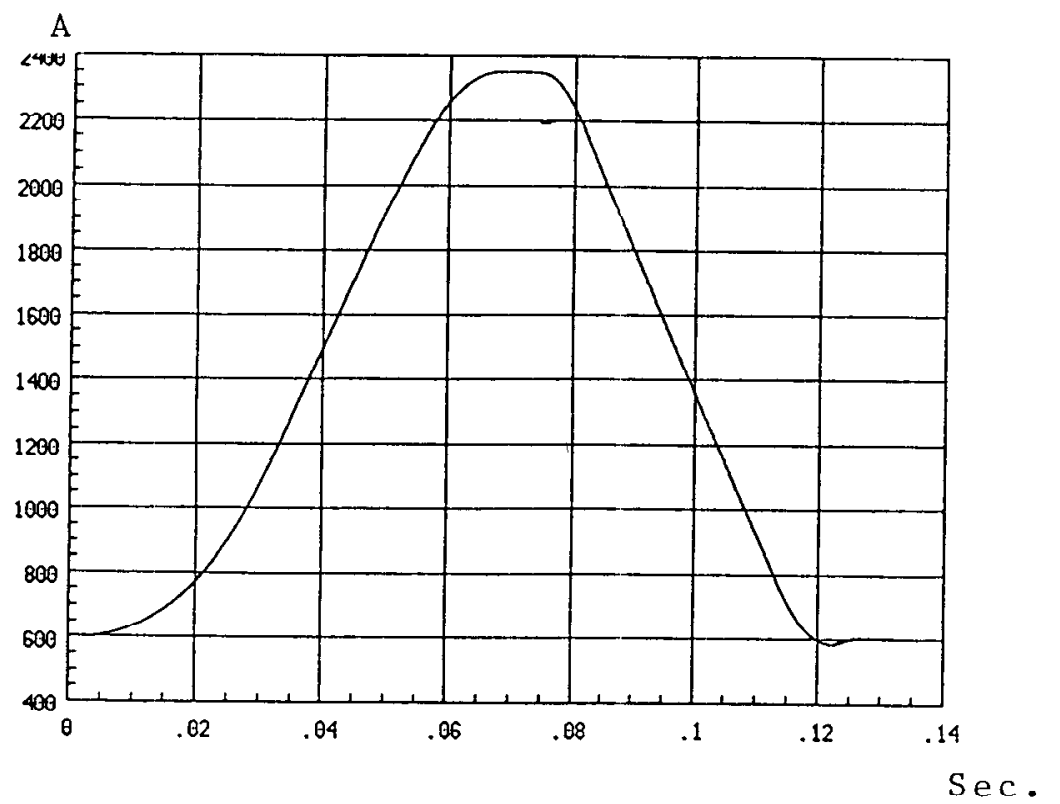

\section{Magnet Current}

Fig. 1.1

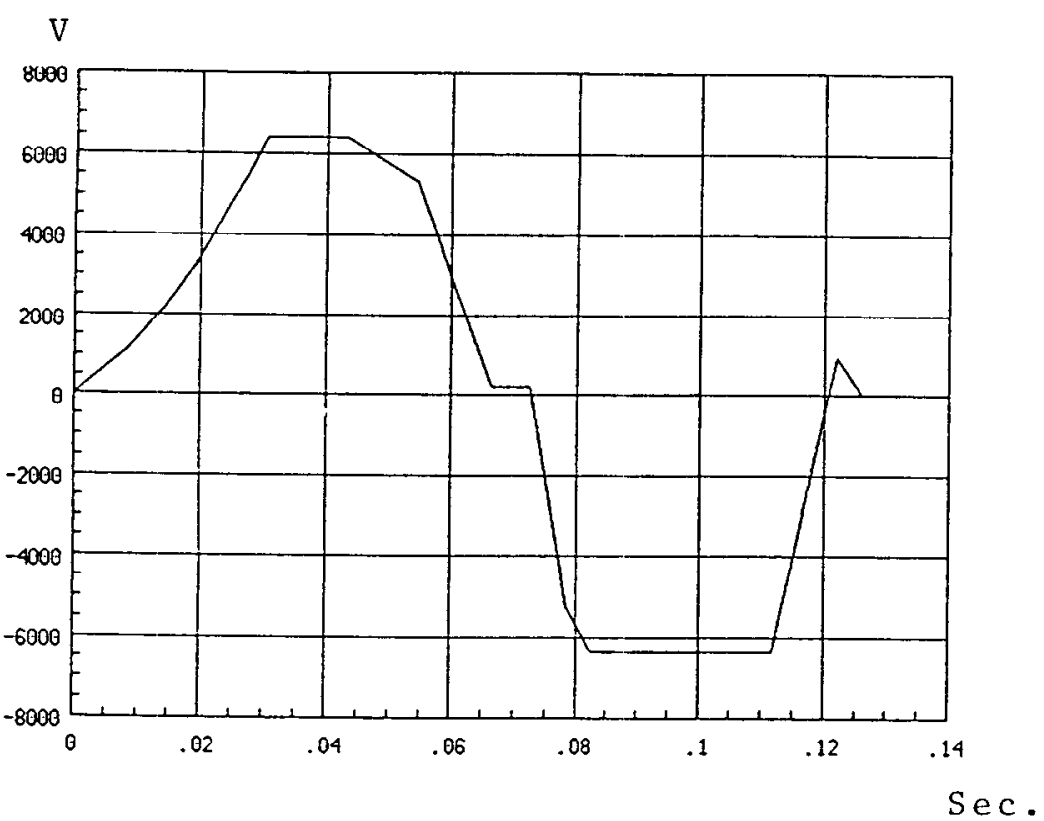

Magnet Voltage Reference

Fig. 1.2

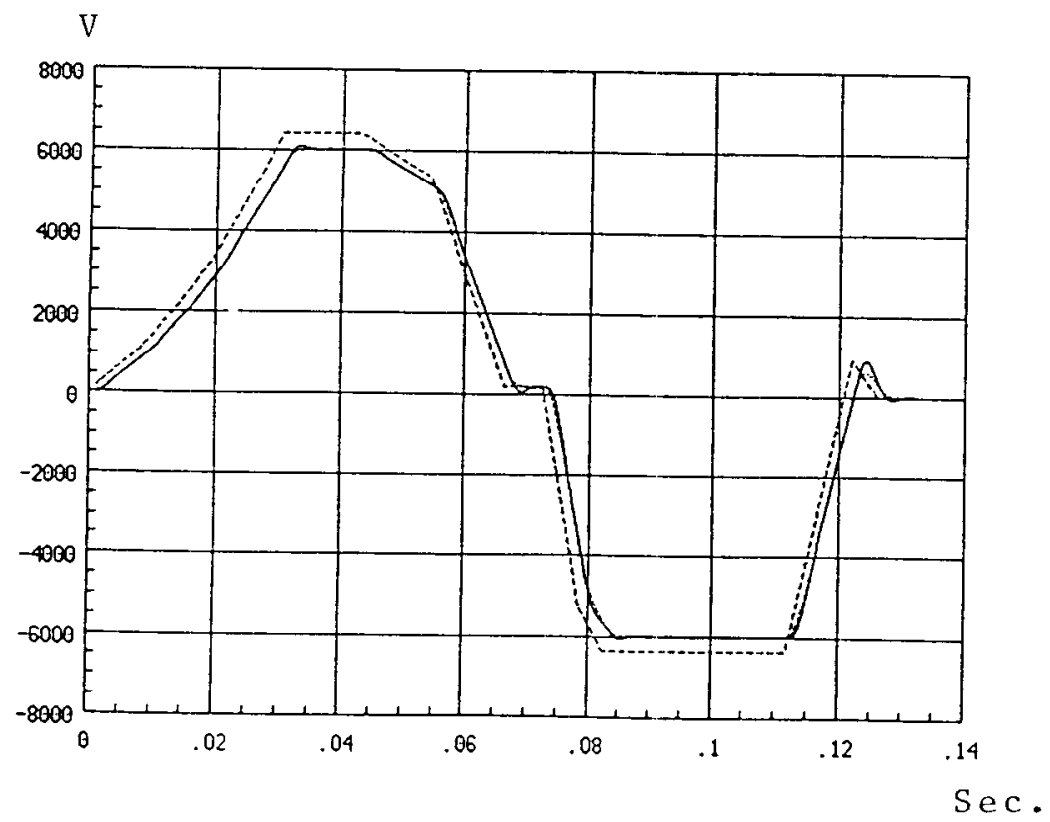

Magnet Voltage (after filter) ... Solid Line

Magnet Voltage(Before filter)

... Dotted Line

Magnet Voltage Reference

... S1ashed Iine

Fig. 1.3 

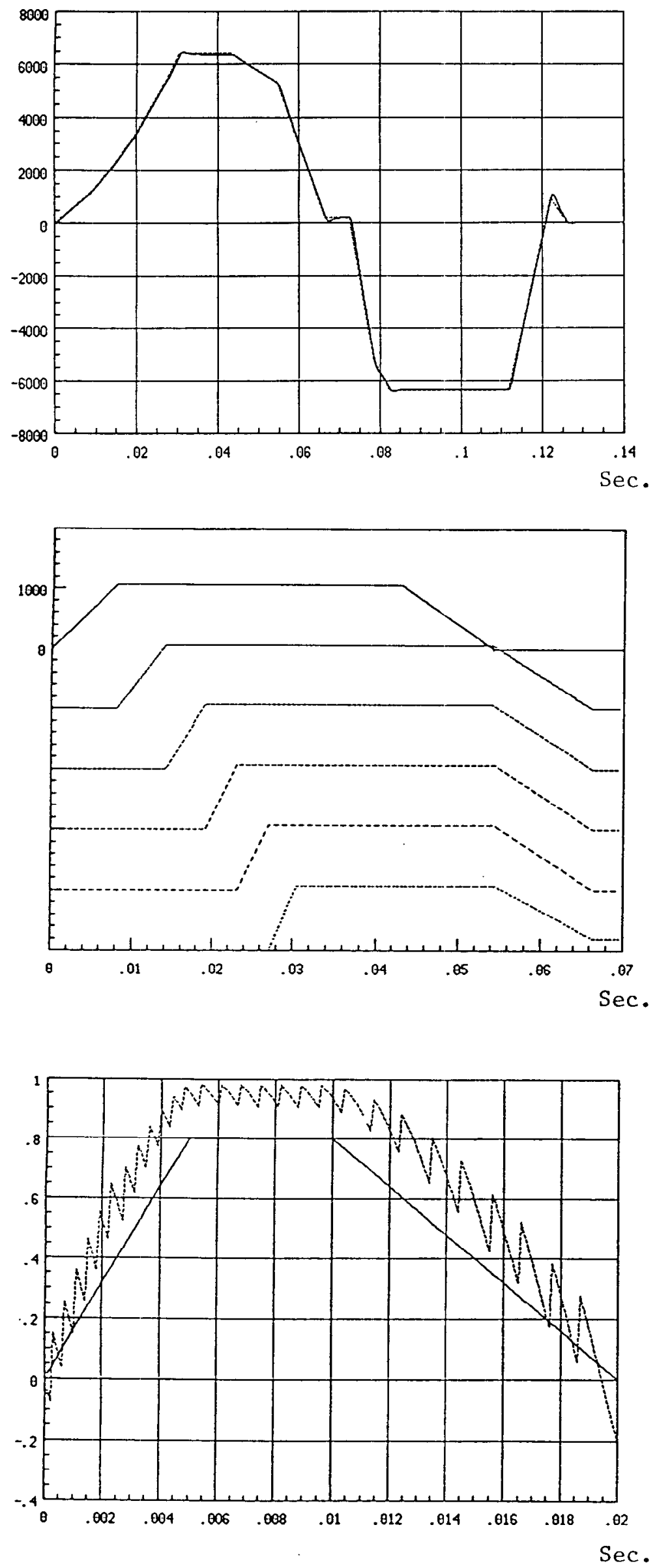

Improved Voltage Tracking

Magnet Voltage

... Solid Line

Reference

... Dotted Line

Fig. 1.4

Voltage References for

6 Stations

Fig. 1.5
Reference for Ramp Comparator ... Solid Line 24 Pulse Converter Voltage Output

... Dotted Line

Fig. 1.6 

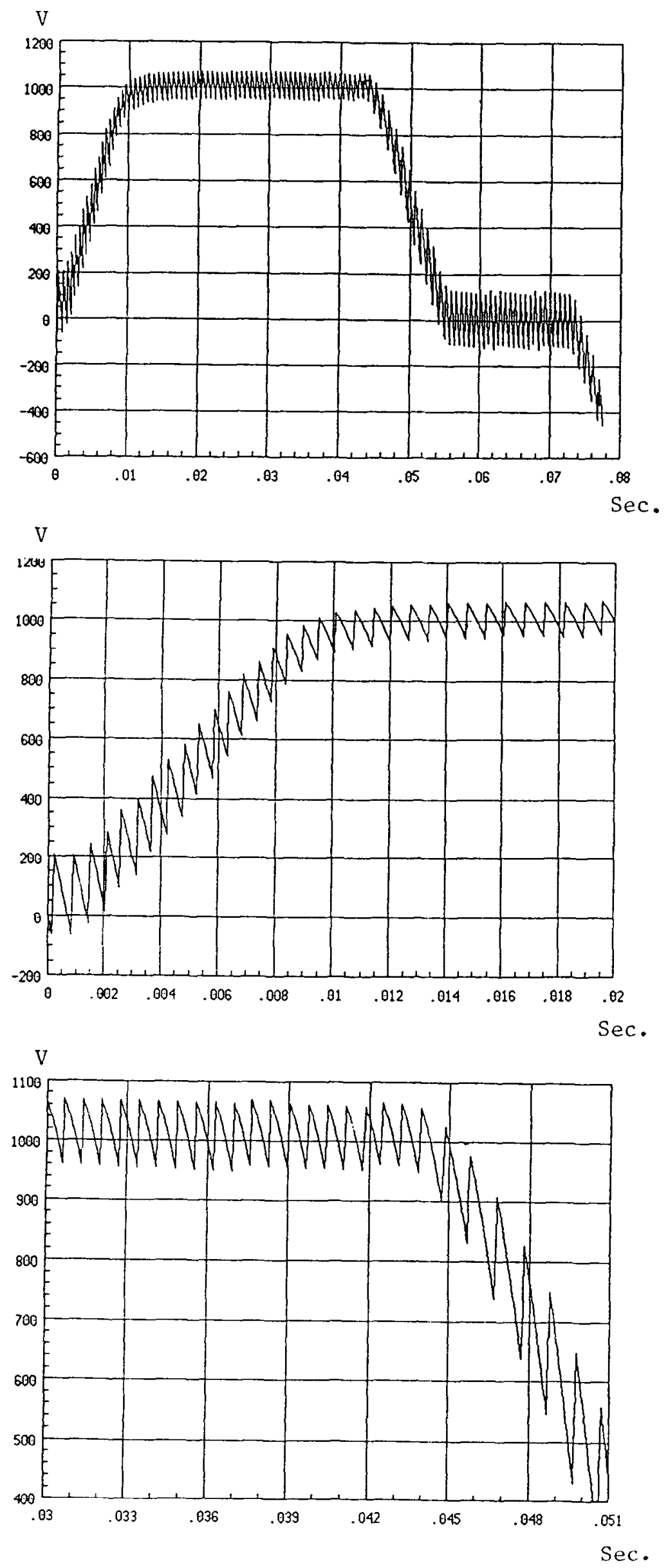

Station 1 Voltage Output

Fig.2.1

Station 1 Voltage Output 0 to $20 \mathrm{~ms}$.

Fig.2.2

Station 1 Voltage Output 30 to $50 \mathrm{~ms}$.

Fig.2.3 

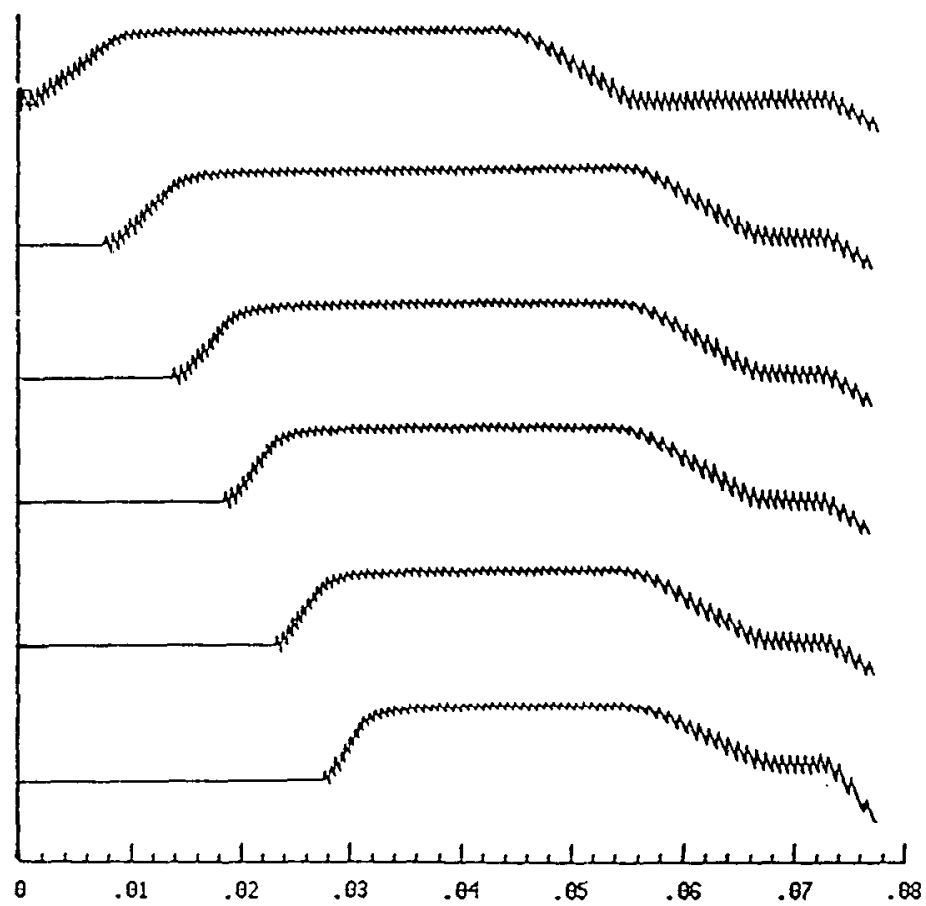

V

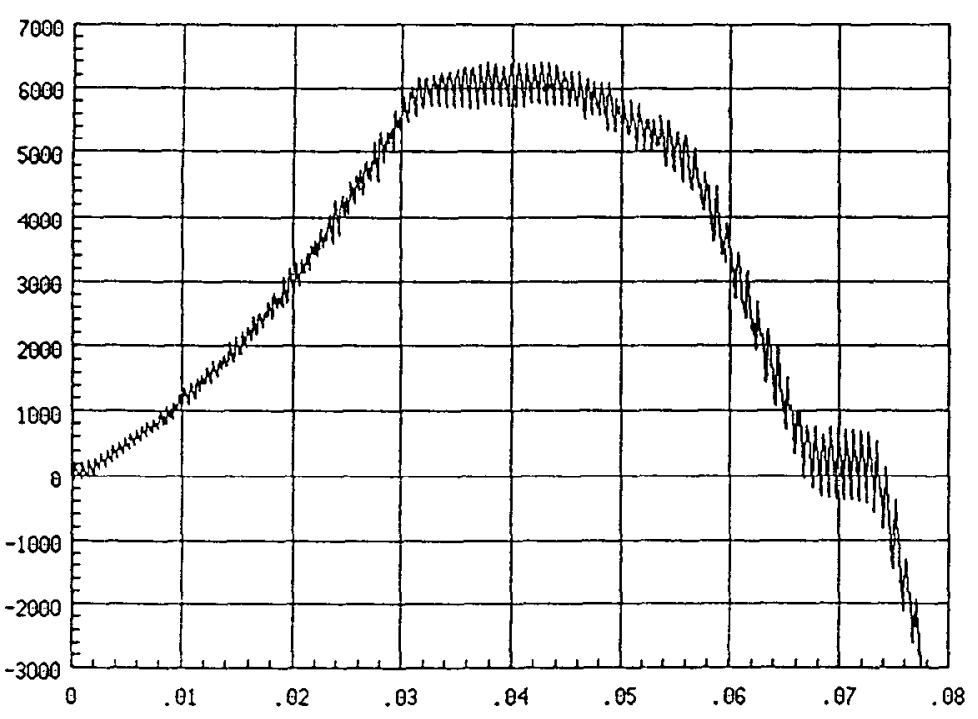

Sec.

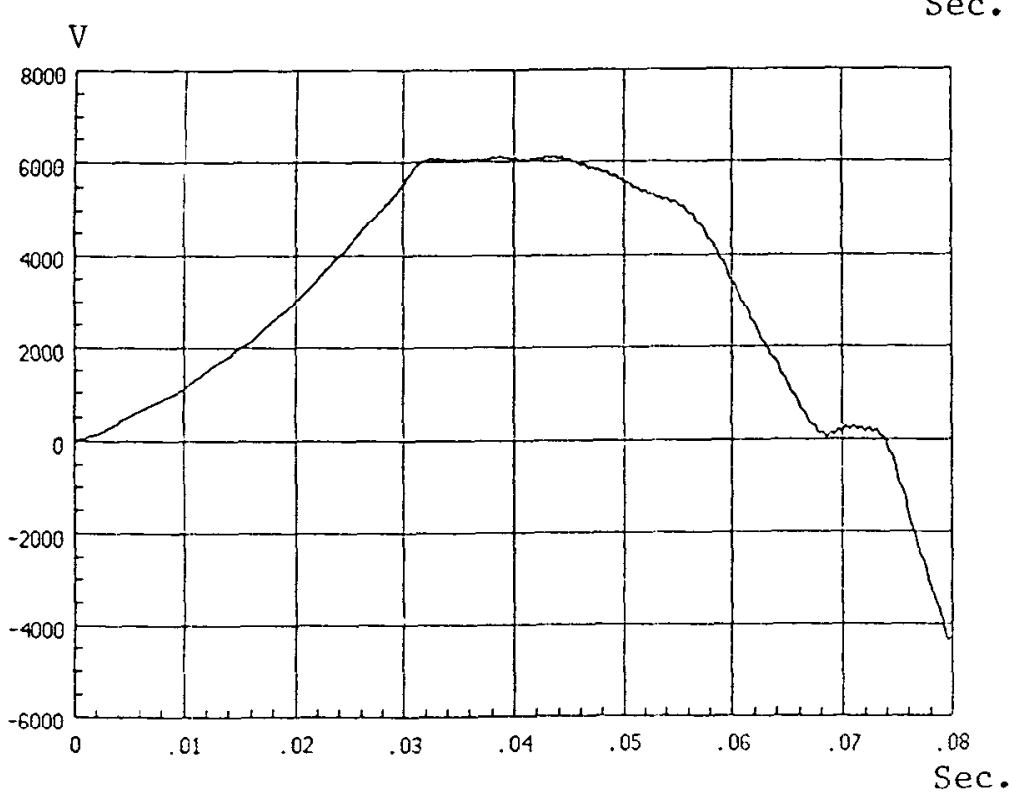

6 Station Voltage Waveforms

Fig. 2.4

Total Magnet Voltage

Fig. 2.5

Magnet Voltage After Filter

Fig.2.6 


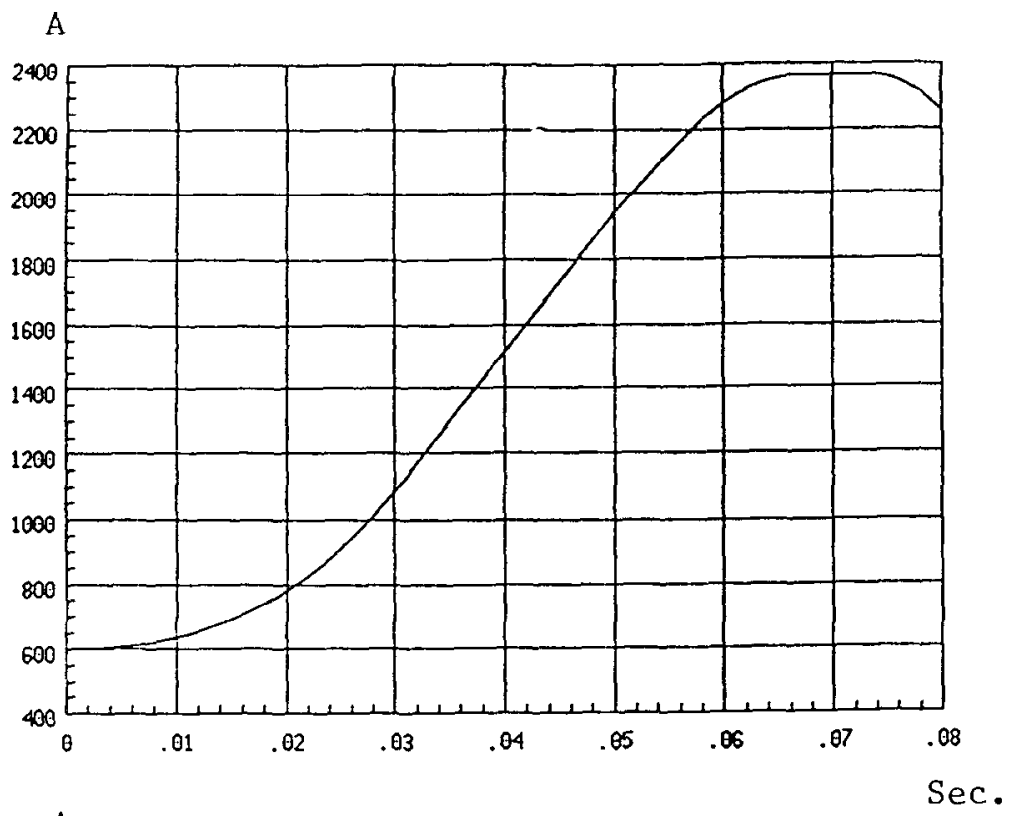

A.

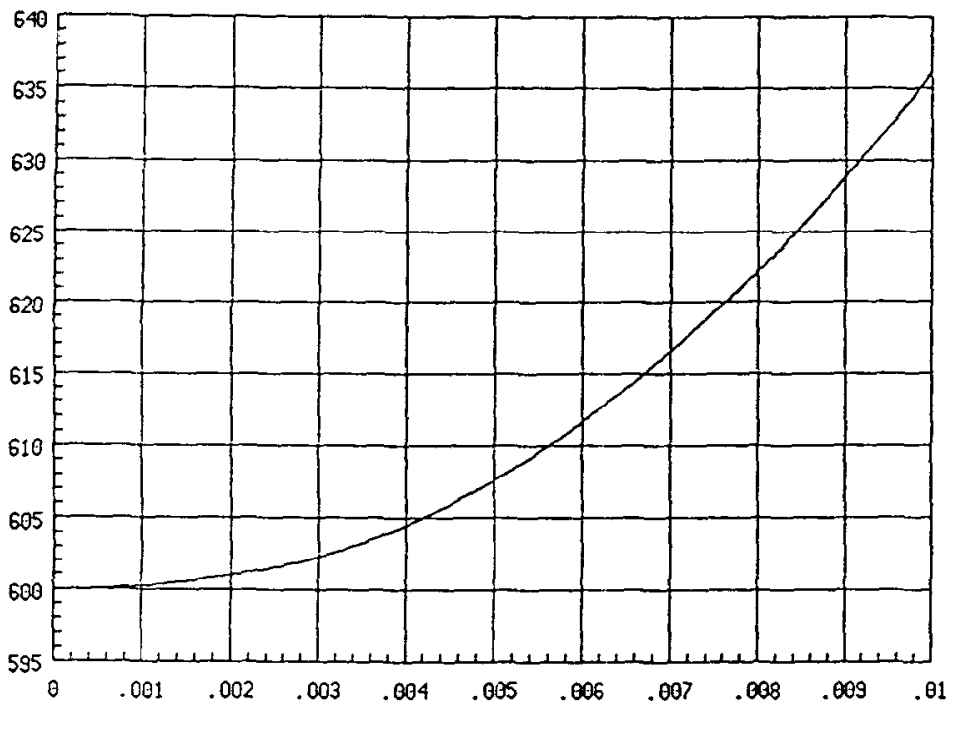

A

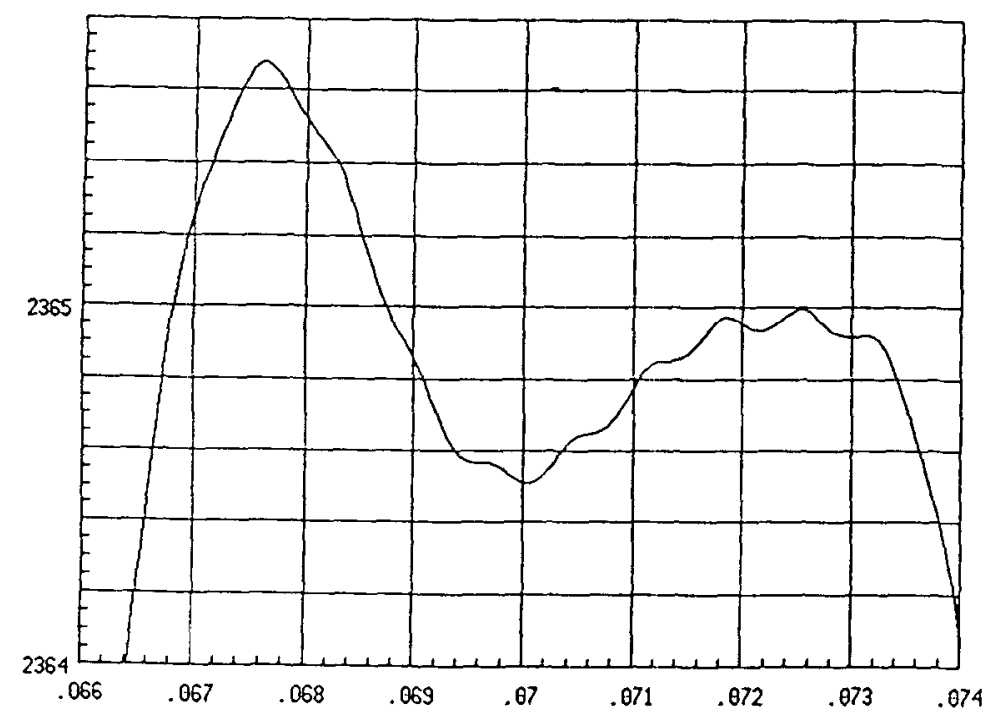

Sec.
Magnet Current

Fig. 2.7

Magnet Current

0 to $10 \mathrm{~ms}$.

Fig. 2.8

Magnet Current at Flatop 66 to $74 \mathrm{~ms}$.

Fig. 2.9 


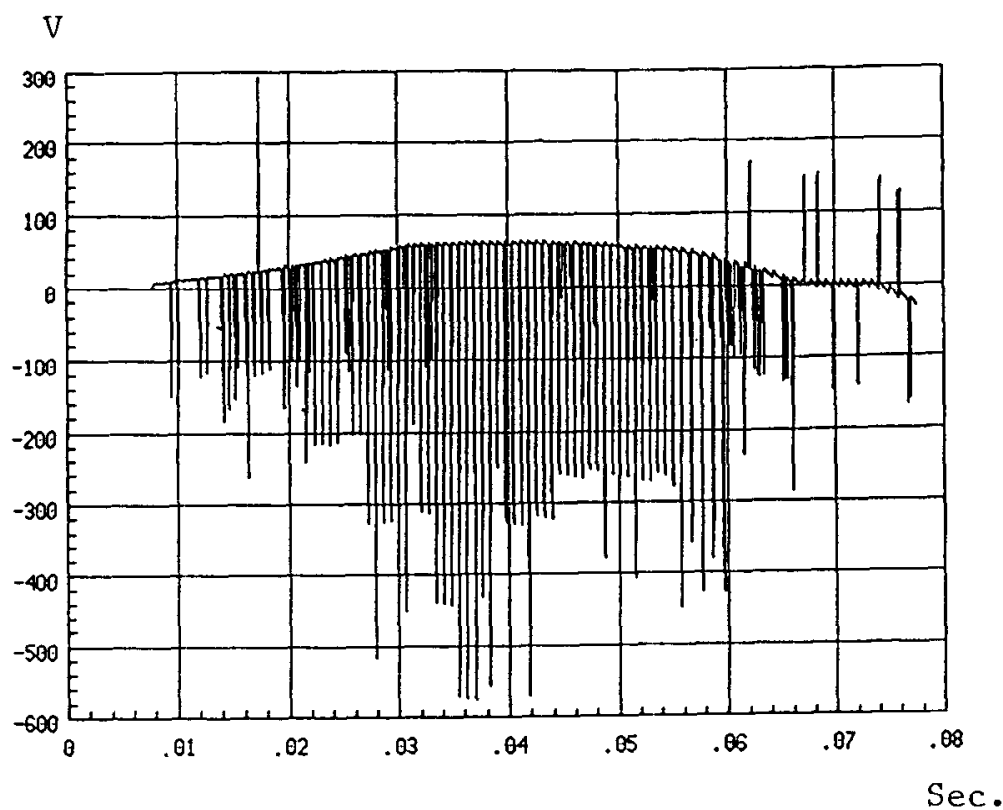

A
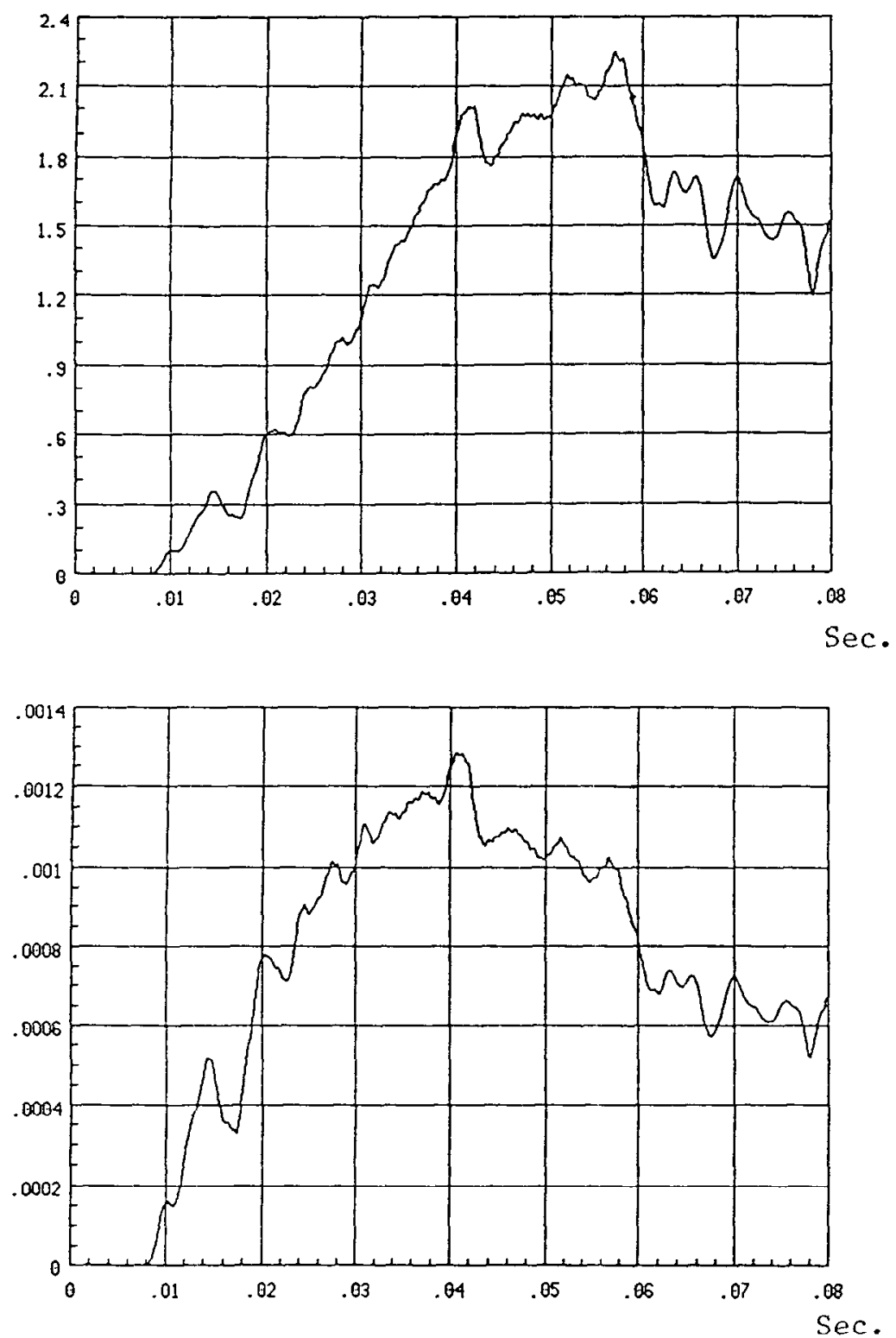

Magnet Voltage Error

Due to $8 \mathrm{~ms} 1 \%$ Step Power

Line Disturbance

Fig.3.1

Magnet Current Error

Due to $8 \mathrm{~ms} 1 \%$ Step Power

Line Disturbance

Fig. 3.2
Magnet Current Error Ratio Due to $8 \mathrm{~ms} 1 \%$ Step Power Line Disturbance

Fig. 3.3 


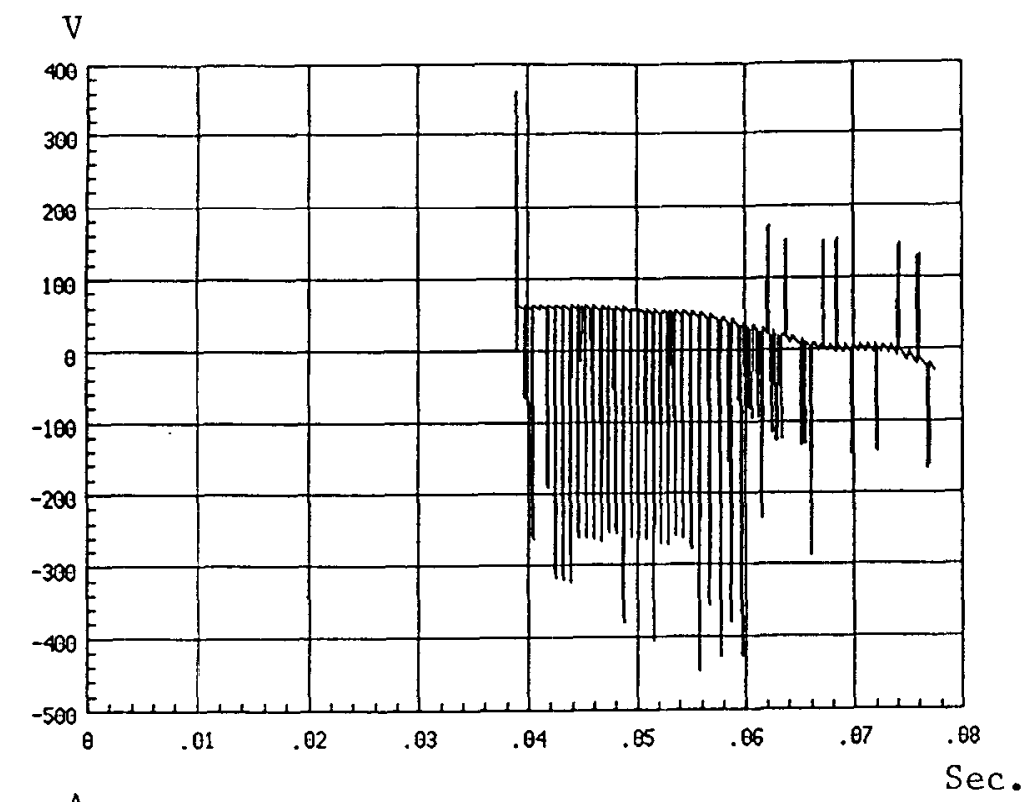

A
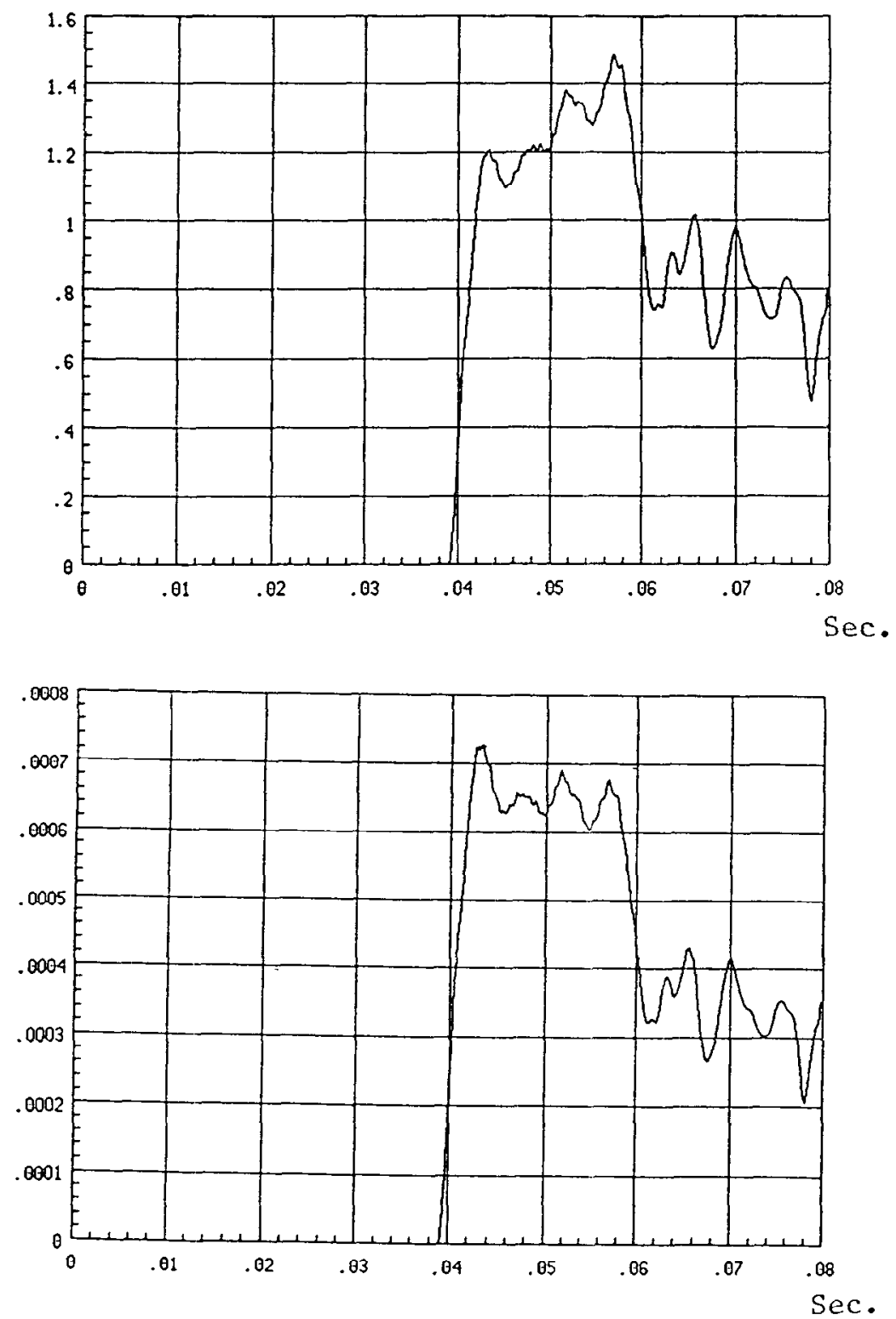

Magnet Voltage Error

Due to $38 \mathrm{~ms} 1 \%$ Step Power

Line Disturbance

Fig. 3.4

Magnet Current Error

Due to $38 \mathrm{~ms} 1 \%$ Step Power

Line Disturbance

Fig. 3.5
Magnet Current Error Ratio

Due to $38 \mathrm{~ms} 1 \%$ Step Power

Line Disturbance

Fig. 3.6 